\title{
The relationship of performance with soft factors and quality improvement
}

\begin{abstract}
The aim of this paper is to examine the influence of soft factors of quality management on firm performance, and analyse the link between quality improvement practice and firm performance. The study used data from 255 electrical and electronics (E\&E) firms in Malaysia and it developed regression and correlation analysis to test these relationships. The findings showed that the following soft factors have significant influence on firm performance: management commitment, customer focus and employee involvement. Finally, this study has empirically shown that firm performance will increase when the organisations implement more quality improvement practices. The results of this study may be used by managers to prioritise the implementation of the soft factors in order to allocate resources to improve firm performance.
\end{abstract}

Keyword: soft factors, quality management, firm performance, electrical and electronics $(\mathrm{E} \& \mathrm{E})$ firms 